\title{
Soft indication turns strong in specific situation
}

\author{
Tamer Zaalouk ${ }^{1}$, zouheir Bitar ${ }^{1}$, and Osama Maadarani ${ }^{1}$ \\ ${ }^{1}$ Ahmadi Hospital
}

August 20, 2020

\begin{abstract}
Patient in sinus rhythm with dilated cardiomyopathy and low ejection fraction $<35 \%$ have a $4 \%$ risk of embolic event (1). This is a soft indication for therapeutic anti-coagulation(controversial) (2). Presence of excess Intra-cardiac Smoke-like Echoes increase risk of embolic event and switch the soft indication to strong one
\end{abstract}

\section{Soft indication turns strong in specific situation}

Tamer Mohamed Zaalouk*, Zouheir Ibrahim Bitar, Ossama Sajeh Maadarani.

Critical Care Unit, Ahmadi Hospital, Kuwait Oil Company P.O.Box 46468 , Postal code 64015 Fahaheel

Corresponding author.Email: tzaalouk@hkockw.com or forevertn@hotmail.com

\section{KEY CLINICAL MESSAGE}

Patient in sinus rhythm with dilated cardiomyopathy and low ejection fraction $<35 \%$ have a $4 \%$ risk of embolic event (1). This is a soft indication to start therapeutic anti-coagulation (controversial) (2). Presence of excess Intra-cardiac Smoke-like Echoes increase risk of embolic event and switch the soft indication to strong one.

\section{Case presentation}

A 48-year-old Asian male with history of ischemic cardiomyopathy with low Ejection fraction (EF 15\%). Received thrombolysis 2 months ago due to Right middle cerebral artery stroke. Presented with low cardiac output state require vasopressors support. patient was receiving anti-platelet medication (aspirin) but no anticoagulation. On repeating ECHO, there is excess intra-cardiac smoke-like Echoes fig (1-2). In the context of old stroke and excess intra-cardiac Smoke -like Echoes the Soft indication for therapeutic anticoagulation turned to Strong indication.

\section{AKNOWLEDGMENTS}

No relevant acknowledgments.

\section{CONFLICT OF INTEREST}

Not declared.

\section{AUTHOR CONTRIBUTIONS}

Tamer Zaalouk and Osama Maadarani collected the information, drafted the manuscript and Zohier Bitar revised and approve the final manuscript.

\section{CONSENT}

Informed consent was obtained from the patient for the publication of this clinical image. 


\section{FUNDING}

The authors received no financial support for the research, authorship, and/or publication of this article. This research was performed as part of authors duties in kuwait oil Company, kuwait.

\section{REFERENCES}

1. Katz SD, Marantz PR, Biasucci L, et al. (1993) Low incidence of stroke in patients with heart failure: a prospective study. Am Heart J 126:141-146.

2. Dunkman WB, Johnson GR, Carson PE, Bhat G, Farrell L, Cohn JN(1993) Incidence of thromboembolic events in congestive heart failure. Circulation 87 (Suppl VI):94-101.

\section{Hosted file}

video 1.mp4 available at https://authorea.com/users/349297/articles/476195-soft-indicationturns-strong-in-specific-situation

\section{Hosted file}

video 2.mp4 available at https://authorea.com/users/349297/articles/476195-soft-indicationturns-strong-in-specific-situation 